\title{
Energy management in connected and disconnected mode of a photovoltaic system with a battery storage using an artificial neural network technique
}

\author{
Ezzitouni Jarmouni ${ }^{1}$, Ahmed Mouhsen ${ }^{2}$, Mohammed Lamhammedi ${ }^{3}$, and Zakarya Benizza ${ }^{4}$ \\ ${ }^{1,3}$ Laboratory of Radiation-Matter and Instrumentation (RMI), The Faculty of Sciences and Technology, \\ Hassan 1st University, Morocco \\ ${ }^{2,4}$ Laboratory of Engineering, Industrial Management and Innovation (IMII), The Faculty of Sciences and \\ Technology, Hassan 1st University, Morocco
}

\begin{tabular}{l}
\hline Article Info \\
\hline Article history: \\
Received Mar 18, 2021 \\
Revised Apr 28, 2021 \\
Accepted May 1, 2021 \\
\hline Keywords: \\
Bidirectional dc/dc \\
Energy management \\
Hybrid grid \\
Neural network \\
Photovoltaic panel \\
Renewable energy \\
Solar battery
\end{tabular}

\begin{abstract}
In order to reduce the inconvenience resulting from the use of the traditional energy sources (oil, gas and coal), the integration of renewable energy sources is among the better solutions. With the integration of green energy sources, there are several strategies that can be adopted, including the combination of clean energy sources (solar, wind, and biomass) with each other, or the combination of renewable sources with conventional sources. In this article, we focus on a photovoltaic system allowing the storage of energy in a battery with a coupling to the electrical grid. In order to overcome the problems related to the random operation that accompanies the use of photovoltaic systems, we have developed a control technique based on the use of artificial neural network technology. The complete system was designed and simulated on MATLAB Simulink.
\end{abstract}

This is an open access article under the CC BY-SA license.

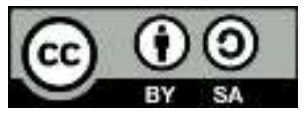

\section{Corresponding Author:}

Ezzitouni Jarmouni

Laboratory of Radiation-Matter and Instrumentation (RMI)

The Faculty of Sciences and Technology, Hassan 1st University, Morocco

BP: 577, route de Casablanca. Settat, Morocco

E-mail : ezzitouni.jarmouni@gmail.com

\section{INTRODUCTION}

Energy is a primordial need for all mankind. However, the real challenge is facing the inevitable depletion of the world's fossil energy resources (oil, gas and coal). The science has recently turned to the socalled clean or renewable energy sources [1], [2]. The most important source of renewable energy is that produced by the sun [3]. According to international renewable energy agency (IRENA), the cumulative installed capacity of solar PV would reach 8519 GW, making it the second largest RES (after wind) by 2050 [4]. However, many technical aspects of smart-grids are not yet solved, such as energy storage integration, power stability, tieline control, and real-time energy management [5].

During the most unfavourable periods (absence of solar radiation) or at night, the use of batteries is necessary for a full-time supply. Even in the presence of of the batteries in photovoltaic installations there is always the possibility of falling into the scenario, of the absence of the nominal conditions "Random operation" of solar panels function, synchronised with the state of discharge of the batteries. In this case there will be a problem with the consumer's power supply 'Critical AC Load'. 
There are several solutions that can be adopted in order to solve this problem, among them: The combination of photovoltaic system with another energy source. For example, wind turbines, diesel group, these solutions may solve the problem but for a limited time, are therefore unreliable. The most widespread and practical solution in this type of case is to connect the installation to the grid [6], [7]. In our work we propose a study on a system mainly composed of a photovoltaic panel that will ensure the generation of electricity, a battery to support the photovoltaic system in the absence of nominal operating conditions, and connection to the public electricity grid. In order to organise the functioning of these elements between them, a new management technique based on neural networks will be proposed. This work is subdivided into three main parts organized as follows: The first part explains the architecture of the studied system and the main components. The second part is concerned with the management and supervision strategy adopted. The last part is dedicated to the analysis and interpretation of the simulation results of the studied system for different operating states. Finally, a conclusion summarizes the work developed.

\section{PRESENTATION OF THE STUDIED SYSTEM}

In the face of growing energy demand, renewable energies are invited to play a decisive role in establishing a sustainable energy strategy. The development of clean and renewable energy resources is the best and safest way to meet the electricity needs of different regions of the world. In this part we will present the studied system, as shown in Figure 1, which is mainly composed of: A photovoltaic panel which will deliver a continuous current [8]. A DC/DC converter with an MPPT "Perturb and observe" controller to reach the point of the maximum power [9], [10], [11]. A solar battery connected to the bidirectional DC/DC converter to ensure the supply of electricity. A DC/AC converter to provide the AC voltage required for the critical load. And a connection to the public electricity grid, in order to ensure the supply of electricity to the consumers, in the case of absence of irradiation for the photovoltaic system, or when the battery state of charge is less than $30 \%$. The system was dseveloped and simulated using the Matlab/Simulink tool.

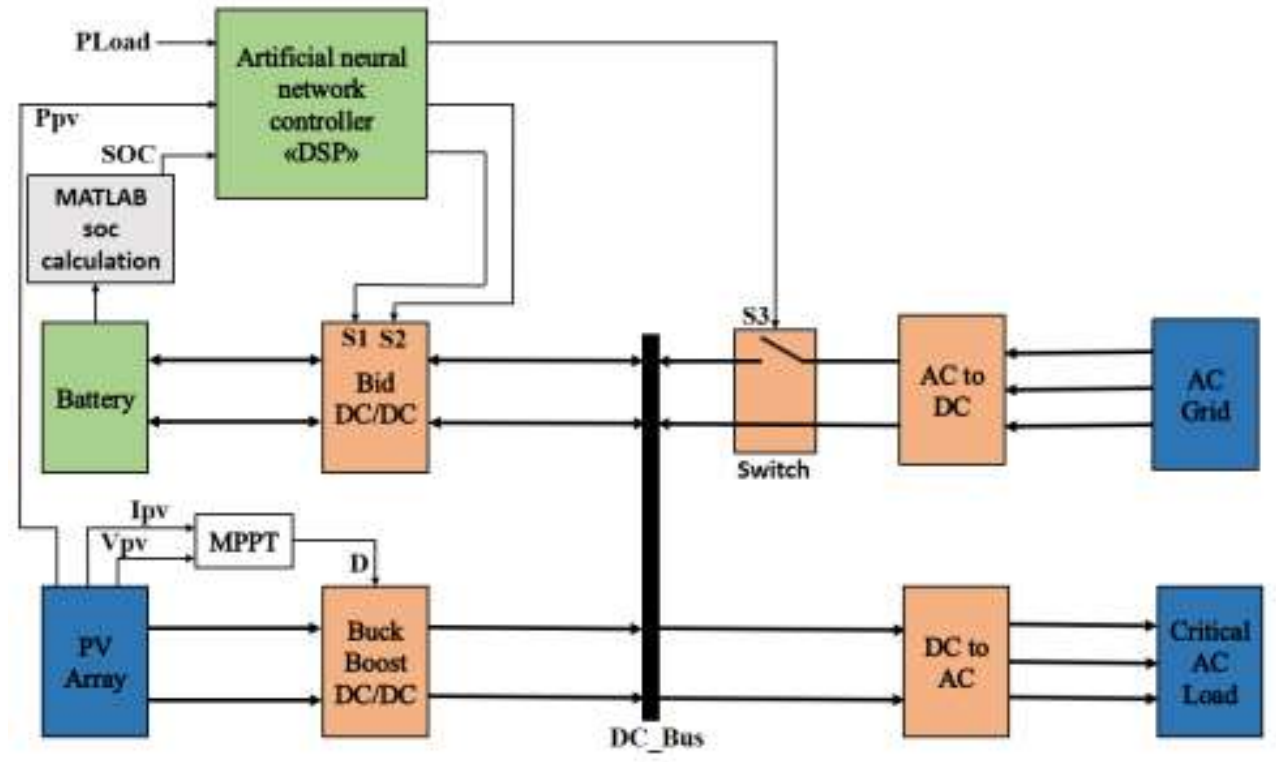

Figure 1. The studied system architecture

\subsection{Bi-directional de-dc converters}

The bi-directional DC-DC converters are used where there is a need to impose power flow in two directions [12], [13], [14]. In our work bidirectional DC-DC converter is a main element, because it is going to ensure the autonomy of operation of our system. To manage the state of charge "soc" of the battery a bidirectional buck-boost converter will be used to ensure the flow of current in both directions (charge/discharge) according to the state of switches S1 and S2, whose commands are generated by the neural network output states" zero or one". Figure 2 shows the corresponding circuit of the converter to be used. 


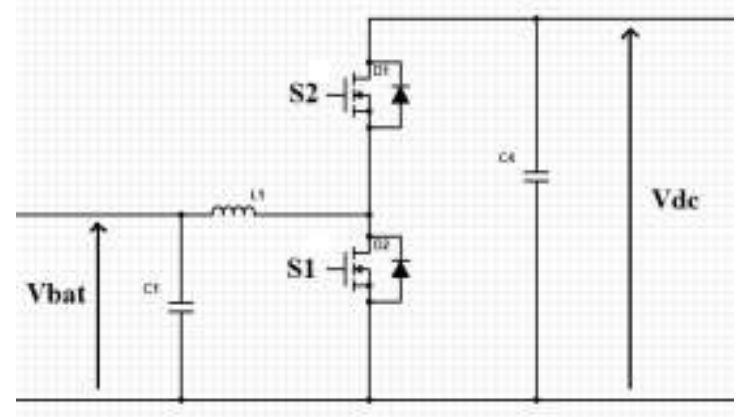

Figure 2. Equivalent circuit of a bidirectional buck-boost converter

\section{SYSTEM MANAGEMENT STRATEGY}

During its use, a battery placed in a stand-alone network can undergo either overload when its soc exceeds 90\%, or deep discharges when its soc decreases below 30\% [15], [16], [17]. Based on these indications we propose a management strategy for a hybrid electric network in order to:

Prevent deep discharges and overcharges of the battery and Ensure continuous power supply for the consumer [18], [19].

This strategy can be organised in four operating modes, as illustrated in the Figure 3:

- Mode 1: "Charge Mode"; This Mode occurs when the power supplied by the photovoltaic source is greater than the power demanded by the load (Ppv > Pload), and battery state of charge and less than $30 \%$.

- Mode 2: "Discharge Mode"; This Mode occurs when the power supplied by the photovoltaic source is less than the power required by the load and battery state of charge, and greater than $90 \%$.

- Mode 3: "Neither charge nor discharge Mode" or "Connected mode"; This Mode occurs when the power supplied by the photovoltaic source is less than the power demanded by the load, and the battery state of charge is also less than $30 \%$. The purpose of this state is to protect the battery from the deep discharge. In this mode, we will have the problem of assuring the supply to the consumer, and as a consequence put a connection between our system and the public electric grid.

- Mode 4: "Neither charge nor discharge Mode"; This state occurs when the power supplied by the photovoltaic system is greater than the power demanded by the load and the battery state of charge greater than $90 \%$. The purpose of this state is to protect the battery from overcharging.

These operating states 'Modes' can be presented on the following diagram.

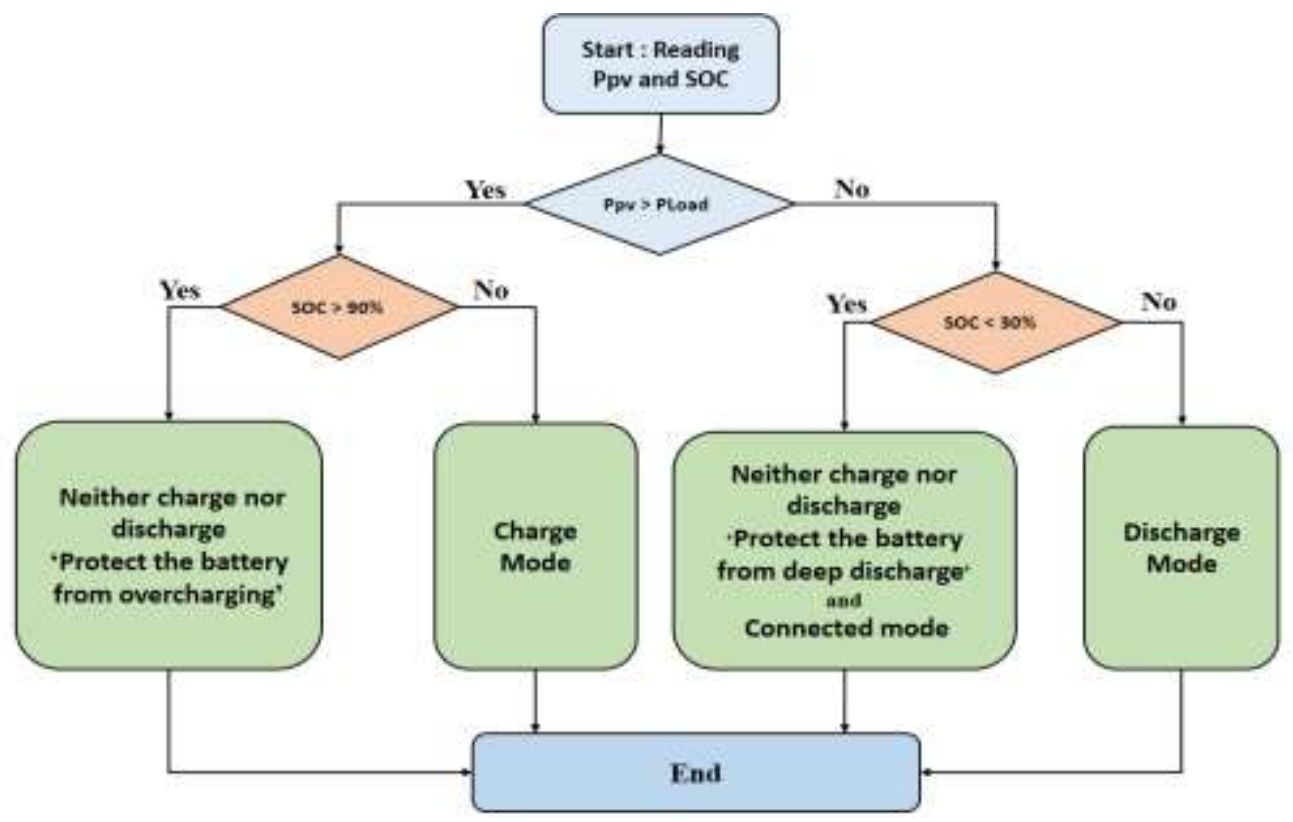

Figure 3. The different system operating modes 


\subsection{Intelligent management strategy.}

The integration of new "artificial intelligence" management technologies in the electrical networks is one of the main objectives of our work. In this part we will develop a management model based on the integration of neural networks in order to manage the system while respecting the four modes of operation mentioned above. With this management technique we will gain in flexibility and robustness of control and we will ensure the continuity of electricity supply to the consumer and at the same time protect the battery and increase their lifespan. Figure 4 illustrates the structure of the proposed neural network model.

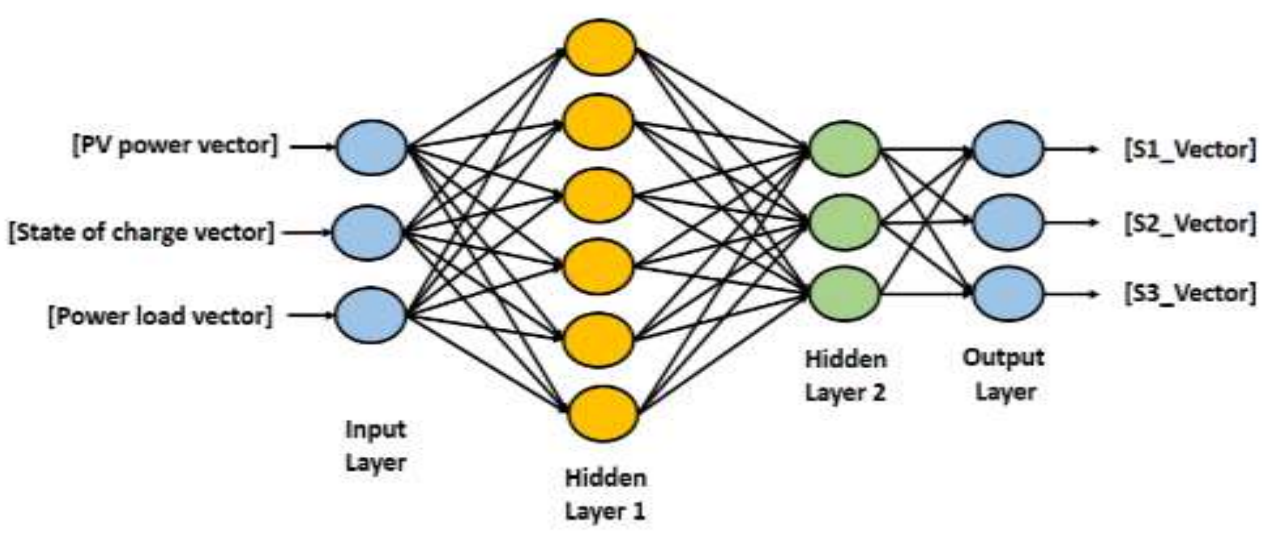

Figure 4. The structure of the proposed artificial neuron network

\subsection{The proposed model}

As shown in Figure 5, the proposed model is a neural network with three inputs vectors representing the power generated by the photovoltaic system, the battery state of charge and the demanded power by the load. The neural network output consisting of three vectors [S1] and [S2] to controls the bi-directional converter, and [S3] to switching between connected and disconnected mode. The dimensions of the input/outputs are "1x2000" for each vector.

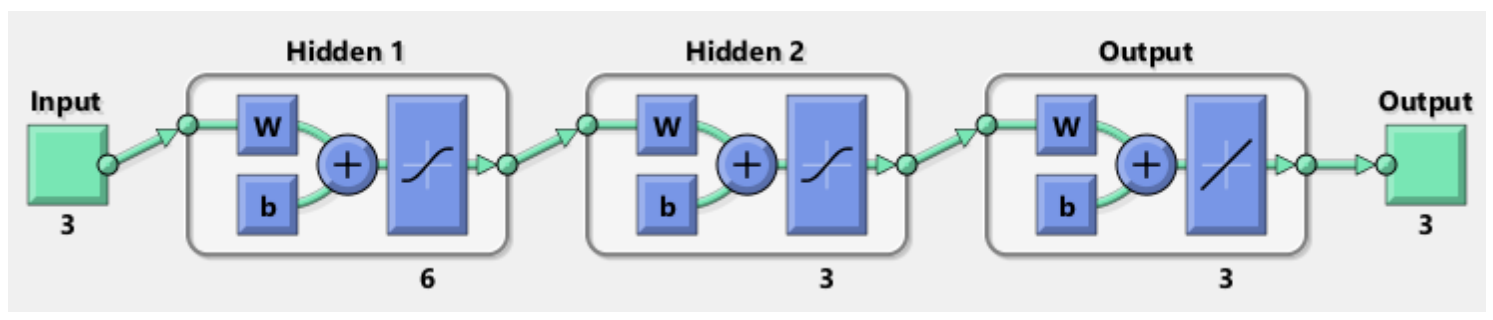

Figure 5. The neural network architecture under MATLAB

\section{SIMULATION AND DISCUSSION OF THE RESULTS}

After the development (Choice of number of hidden layers, number of neurons per layer, activation function and network optimization function.) and the neural network simulation under Matlab [20],

[21], [22], [23], [24], we generate the Simulink files, the latter containing all the information about our network and the management strategy we have adopted.

\subsection{Training of the neural network:}

In this part, we will present the different factors that prove the robustness and reliability of the control system developed. Figure 6 shows the number of iterations and the time needed to get to the minimum possible error value (the convergence of the outputs to the desired outputs).

The verification of the convergence of the learning algorithm is done by the learning curve given in Figure 7 , where we can see that the value of the error target is equal to $1.3627^{*} 10^{-8}$ at 132 epochs, and this value is very enough to give a good classification rate. This implies that the network parameters (weight and bias) are well calculated, then the system management by neural network will be done in a perfect way [25]. 


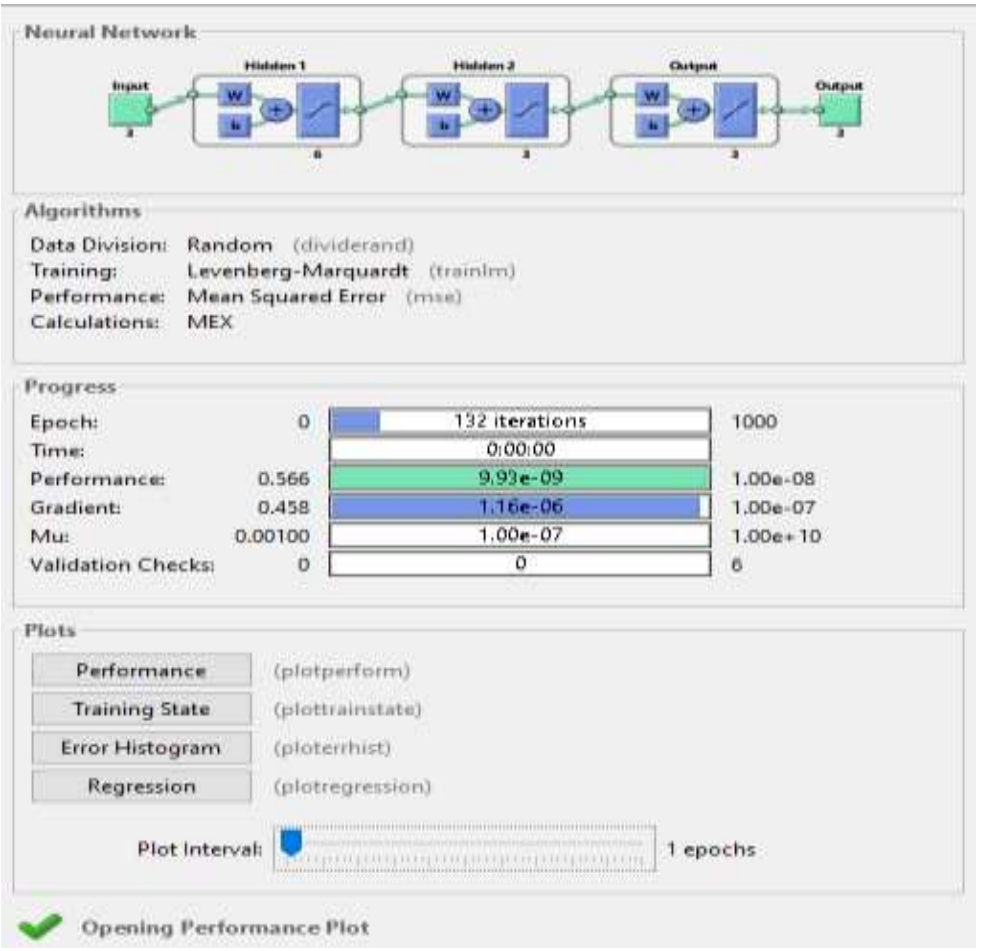

Figure 6. ANN training in MATLAB/Simulink

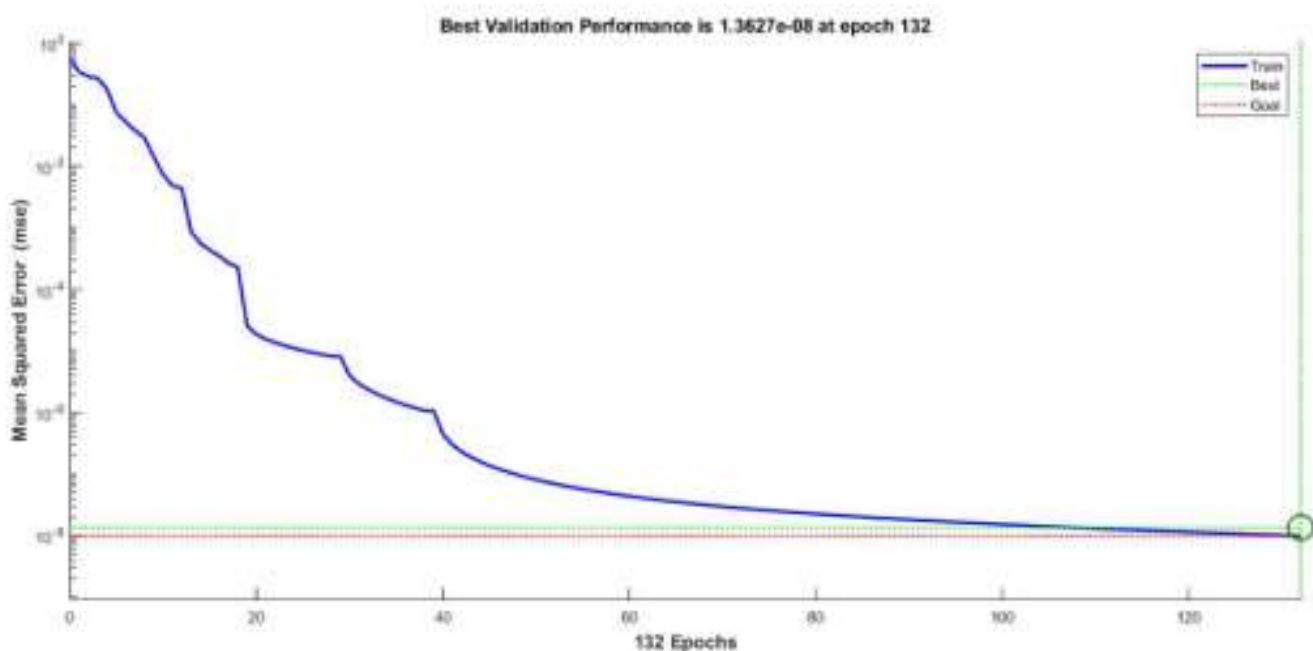

Figure 7. The squared error of the ANN training with MATLAB/Simulink

\subsection{Testing of the control system in different cases}

In this section, we try to test the efficiency of the "neural network" management system, under different test conditions. To better analyse the efficiency and reliability of our control system, we choose to assign values to the soc that are $90 \%$ higher or $30 \%$ lower. In this way we will show that if we are above the soc value is $90 \%$, and the power of the source ' $\mathrm{Ppv}$ ' is higher than the reference value 'PLoad', we will notice that the control system will impose the battery to switch to non charging mode, in order to protect the battery from overcharging.

In the other case when the lower power required by the load is higher of the source, and the battery state of charge is less than $30 \%$. The system imposes on the battery the non-discharge mode in order to protect the battery from deep discharge. And at the same time switches to the connected mode in order to ensure supply to the consumer. All this we will present it in the three cases below: 


\subsubsection{Case N 1}

In this case the battery charge mode is considered to be $95 \%$ with variable power from the source. For a better analysis of all the graphs in Figure 8, we have chosen to divide the analysis into three time intervals.

- The first interval from 0s to 3s: During this interval we see that the power generated by the photovoltaic system (Ppv) is lower than the reference power (PLoad) " $2 \mathrm{kw}$ ", and that the state of charge of the battery is greater than $90 \%$. Therefore, we will have the state: $\mathrm{S} 1=1, \mathrm{~S} 2=0$ and $\mathrm{S} 3=0$. This is the battery discharge mode 'in order to compensate the energy demanded by the consumer'.

- The second interval from 3s to 7s: During this interval, we see Ppv > Pload and soc > 90\%. Therefore, we will have the state: $\mathrm{S} 1=0, \mathrm{~S} 2=0$ and $\mathrm{S} 3=0$. This is the no-charge and no-discharge mode "protection of the battery against overcharging".

- The third interval from 7s to 10s: During this interval, it shows that Ppv < PLoad, and soc > 90\%. Therefore, the state produced is: $\mathrm{S} 1=1, \mathrm{~S} 2=0$ and $\mathrm{S} 3=0$. This is the discharge mode of the battery.

- In this case, there is an autonomous 'hybrid' operation of the system, where the power required by the load is provided by the photovoltaic system or the battery.

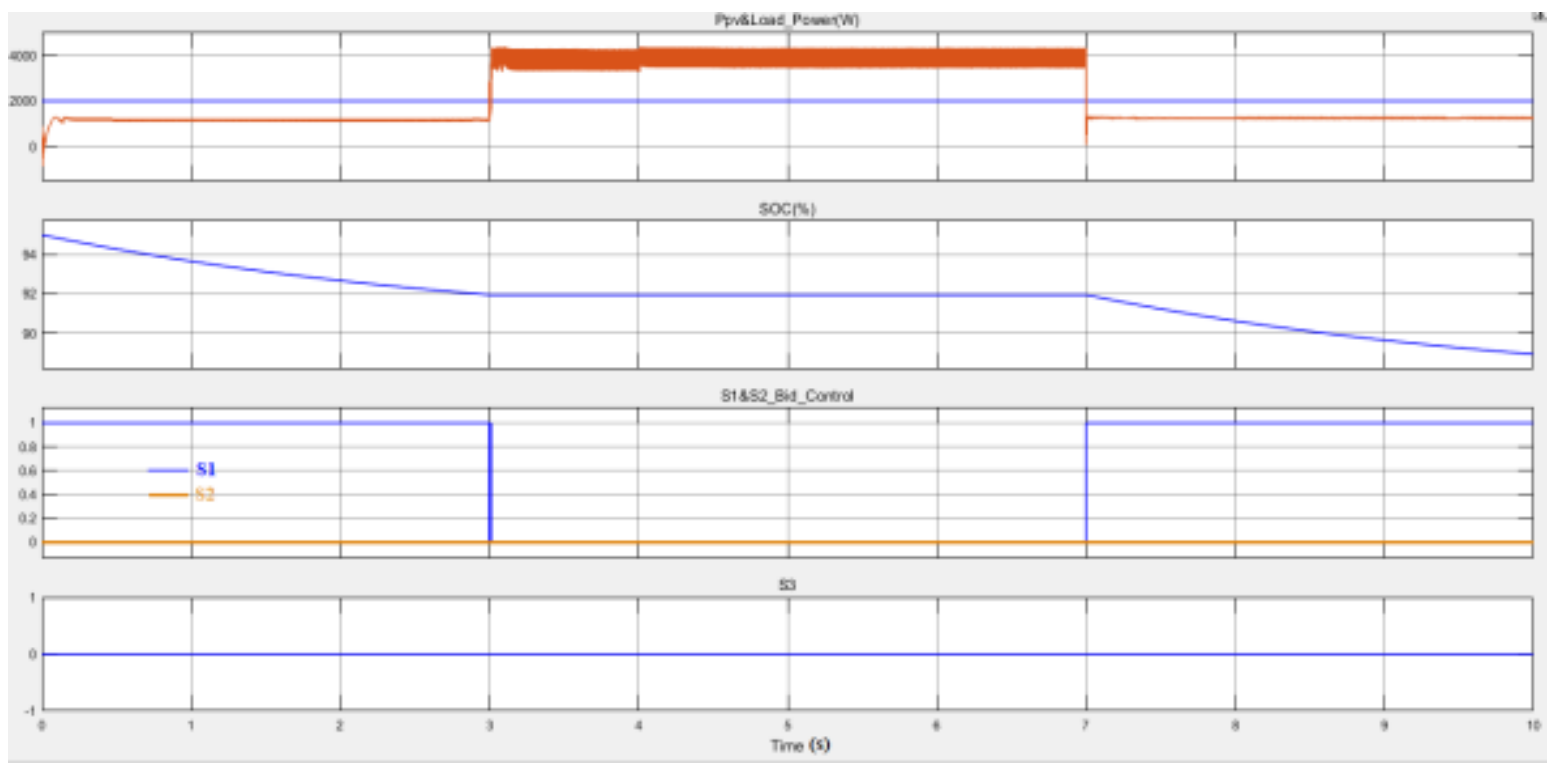

Figure 8. List of the representative graphs of of case $\mathrm{N}^{\circ} 1$

\subsubsection{Case $N 2$}

In this case, we have considered that the state of charge of the battery is equal to $22 \%$ and a variable power of the source. In order to better analyze all the graphs of Figure 9, we have chosen to classify it in three intervals:

- The first interval from 0s to 3s: During this interval, we see that Ppv $<$ PLoad, and soc $<30 \%$. As a consequence of these conditions, we will have the state: $\mathrm{S} 1=0$ and $\mathrm{S} 2=0$, and $\mathrm{S} 3=1$, the control system imposes the switchover to grid-connected mode, in order to ensure the power demand of the consumer and battery charging from the public electric grid 'In order to ensure the continuous supply of the load and battery charge'.

- The second interval from 3s to 7s: During this interval, we notice due Ppv $>$ PLoad and soc $<30 \%$. This will give the status: $\mathrm{S} 1=0, \mathrm{~S} 2=0$ and $\mathrm{S} 3=0$. As a result of this case we will have the disconnected mode, the supply and charging of the battery is done from the solar panels.

- The third interval from 7s to 10s: During this interval, we observe that Ppv < PLoad, and soc $<30 \%$. In this case, switch states will have $S 1=0, S 2=1$ and $S 3=1$. As a consequence of this case, we will have the connected mode again, because the battery state of charge is less than $30 \%$, the battery charge and the power compensation required by the charge is done from the public grid. 


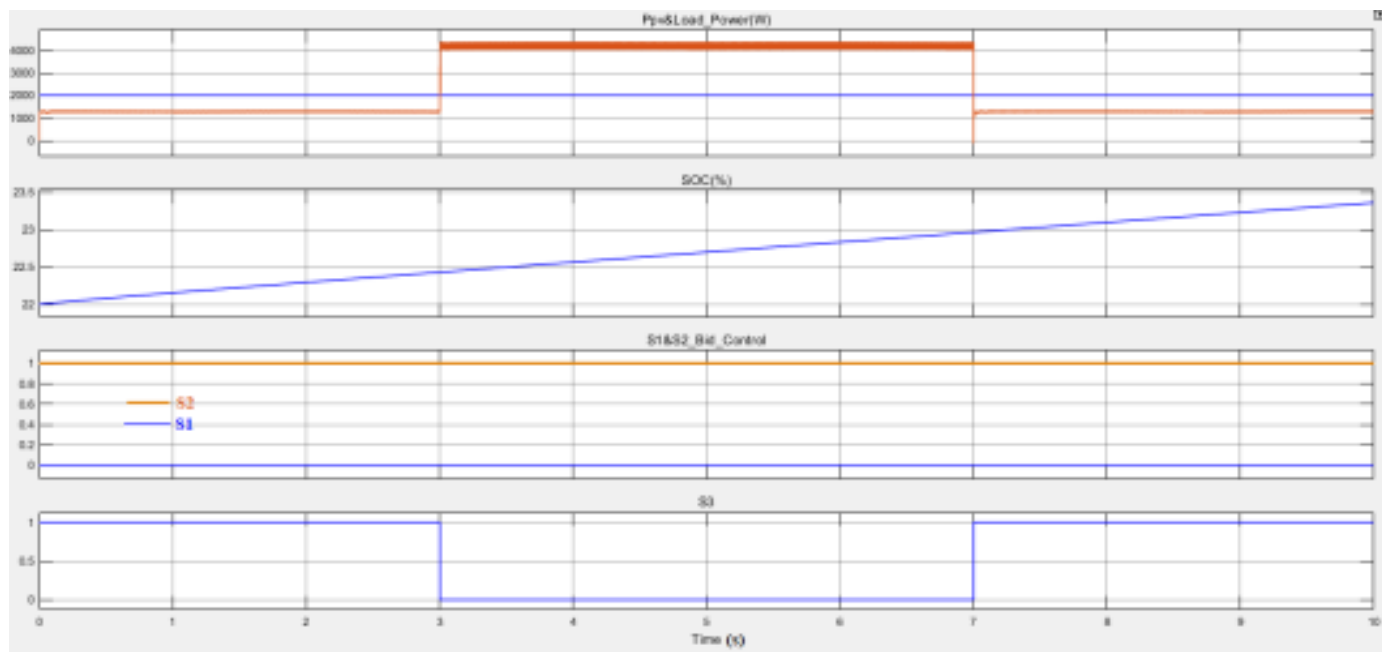

Figure 9. List of the representative graphs of case $\mathrm{N}^{\circ} 2$

\subsubsection{Case $\mathrm{N}^{\circ} 3$}

The objective of this study is to characterise the normal operation of the battery away from overcharges and deep discharges. In order to characterise this case, the battery state of charge was assigned a value equal to $50 \%$, and the power of the source was kept variable.

To analyse this case, the simulation time can be divided into three time intervals as shown in the Figure 10:

- The first interval starts from 0s to 3s: During this interval it can be seen that Ppv <PLoad, and that the state of charge of the battery is equal to $50 \%$ at the start, as a consequence of these conditions we will have the state: $\mathrm{S} 1=1$, and $\mathrm{S} 2=0$ and $\mathrm{S} 3=0$. "Discharge of the battery".

- The second interval ranging from $3 \mathrm{~s}$ to $7 \mathrm{~s}$ : During this interval it can be seen that Ppv >PLoad, and since the SOC is in the vicinity of $50 \%$. The consequence of these conditions is the state: $\mathrm{S} 1=0, \mathrm{~S} 2=1$ and S3 $=0$. "battery charge".

- The third interval goes from 7s to 10s: During this interval it can be seen that Ppv <PLoad, and that the soc is in the vicinity of $50 \%$ so the state produced is: $\mathrm{S} 1=1, \mathrm{~S} 2=0$ and $\mathrm{S} 3=0$. "Discharge of the battery".

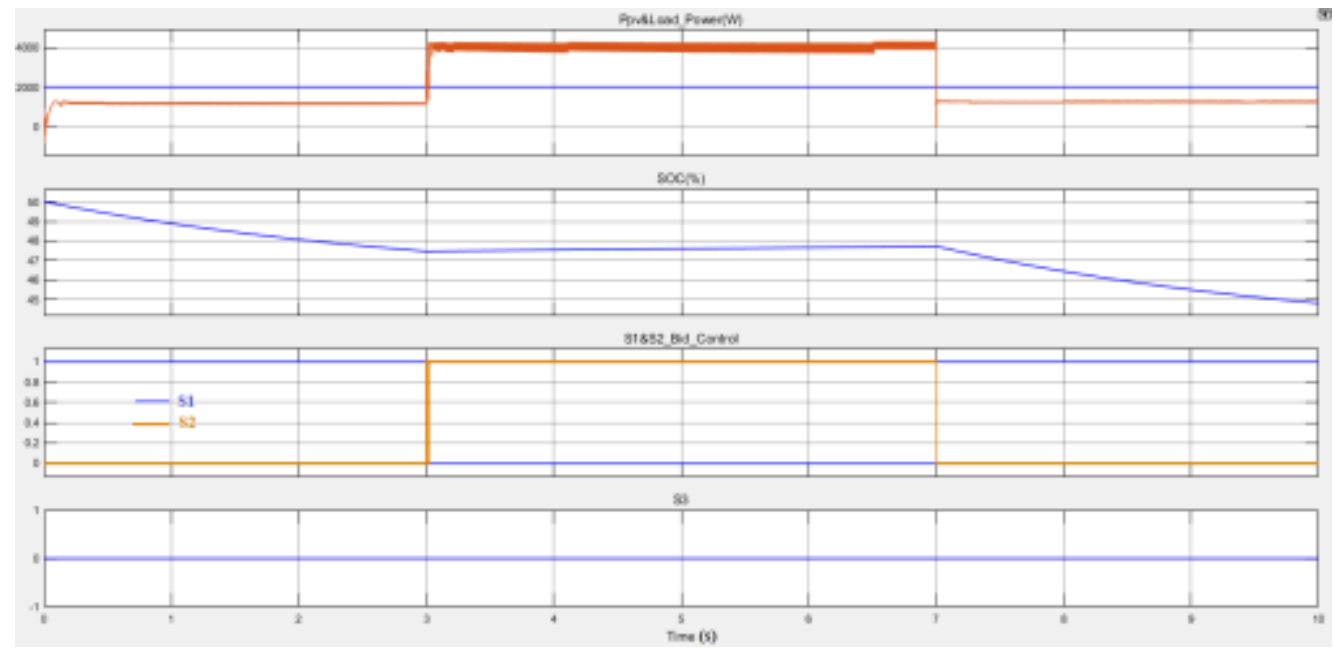

Figure 10. Normal operating:" charge and discharge"

With this energy management technique, based on artificial neural networks, we will gain in terms:

- Intelligent energy management (reasoning similar to human reasoning).

- The robustness of the control system. 
- The simplistic has the implementation.

- The protection of the battery against overcharge and deep discharge.

- Reducing the cost of electrical energy, by using the photovoltaic system as much as possible.

\section{CONCLUSION}

Today the production of electrical energy from solar energy is a promising project. Because solar energy is clean, it does not cause any serious environmental problems compared to conventional energy production sources. Due to the random operation of photovoltaic systems, it is necessary to store the energy produced in order to use it in the absence of optimal production conditions. Batteries offer a well storage solution. However, there is always the possibility that the battery will be discharged at the same time with the absence of solar irradiation. A connection to the public grid is an effective solution, if the system is well managed. In this paper, we have proposed a new technique for electrical energy management based on neural networks, in order to ensure a continuous supply to the consumer and to protect the system components such as the battery in various operating conditions.

\section{ACKNOWLEDGEMENTS}

The authors are very much thankful to the unanimous reviewers of the paper and editor of the journal for their constructive and helpful comments that improved the quality of the paper.

\section{REFERENCES}

[1] N. L. Panwar, S.C. Kaushik," Renewable and Sustainable Energy Reviews”, Science direct, vol. 15, pp. 1513-1524, April 2011.

[2] S. Sumathi and L. Ashok Kumar and P. Surekha, "Solar PV and Wind Energy Conversion Systems", International Publishing AG Switzerland, 2015.

[3] M. Ö. Arioglu, A. A. Selam, S. U. Firat, "Renewable Energy Sources: Comparison of their Use and Respective Policies on a Global Scale", in Business Science Reference (an imprint of IGI Global), doi: 10.4018/978-1-52250440-5.ch011.

[4] IRENA, "Future of Solar Photovoltaic: Deployment, investment, technology, grid integration and socio-economic aspects", 2019.

[5] E. Kremers, P. Viejo, O. Barambones, and J. Gonzalez de Durand, "Proceedings of the 2010 15th IEEE International Conference on Engineering of Complex Computer Systems (ICECCS '10)”, St. Anne's College, University of Oxford, UK, 22-26 March 2010, pp. 302-311.

[6] V. Karthikeyan, S. Rajasekar, V. Das, P. Karuppanan and A. K. Singh, "Grid-Connected and Off-Grid Solar Photovoltaic System", Green Energy and Technology, doi: 10.1007/978-3-319-50197-0_5.

[7] M. Hafeez, M. Hariri, M. K. M. Desa. Muhammad Ammirrul Atiqi Mohd., "Zainuri Grid-Connected PV Generation System Components and Challenges": A Review, Energies 2020, 13(17), 4279 doi: 10.3390/en13174279.

[8] Hamza, H.A.; Auwal, Y.M.; Sharpson, M.I. "Standalone PV System Design and Sizing for a Household in Gombe", Nigeria. Int. J. Interdiscip. Res. Innov. 6, pp. 96-101, 2018.

[9] A. M. Atallah, A. Y. Abdelaziz," Implementation of perturb and observe mppt of pv system with direct control method using buck and buck boost converters," Emerging Trends in Electrical, Electronic Instrumentation Engineering: An international Journal, vol. 1, February 2014.

[10] T. Esram, P. L. Chapman," Comparison of Photovoltaic Array Maximum Power Point Tracking Techniques," IEEE Transactions on Energy Conversion, Vol. 22, No. 2, 2007.

[11] N. Kacimi, S. Grouni, A. Idir, M. S. Boucherit, "New improved hybrid MPPT based on neural networkmodelpredictive control-Kalman filter for photovoltaic system", Indonesian Journal of Electrical Engineering and Computer Science”, Vol. 20, No. 3, pp. 1230-1241, December 2020.

[12] A. Mendoza-Torres, N. Visairo," Switching rule for a bidirectional DC/DC converter in an electric vehicle" in https://www.sciencedirect.com/science/article/abs/pii/S096706611830594X Vol. 82, pp. 108-117, January 2019.

[13] B.L. Narasimharaju, S.P. Dubey," Design and analysis of coupled inductor bidirectional DC-DC convertor for high-voltage diversity applications", in IET Power Electronics Vol. 7, pp. 998 - 1007, August 2012.

[14] R. Thumma, V. V. S. K. Bhajana, P. K. Aylapogu,"Design and Simulation of a New ZVT Bi-directional DCDC Converter for Electric Vehicles", Indonesian Journal of Electrical Engineering and Computer Science, Vol. 7, No. 1, pp. 75-83, July 2017.

[15] Zaheeruddin, M. Manas, "Renewable energy management through microgrid central controller design: An approach to integrate solar, wind and biomass with battery", IET Power Electronics Vol. 1, pp. 156-163, November 2015.

[16] A. Merabet, K. T. Ahmed, "Energy Management and Control System for Laboratory Scale Microgrid Based WindPV-Battery", in IET Power Electronics Vol. 8, pp. 145-154, Jan. 2017. 
[17] C. Zhang; L. Y. Wang," Robust and Adaptive Estimation of State of Charge for Lithium-Ion Batteries", in IET Power Electronics Vol. 62, pp. 4948-4957, August 2015.

[18] N. Mazi, T. Alamo," Energy management strategies for smart grids," https://hal.archives-ouvertes.fr/tel01472704, thesis, March 2017.

[19] Muhardika, Syafii, "Design of arduino-based loading management system to improve continuity of solar power supply", Indonesian Journal of Electrical Engineering and Computer Science, Vol. 20, No. 3, pp. 1677-1684, 2020.

[20] S. Chen, Z. He," How Big Data and Highperformance Computing Drive Brain Science", in Journal Pre-Proofs Vol. 4, pp. 381-392, August 2019.

[21] S. Stauba, E. Karamanb, S. Kayaa and H. KarapÕnara,"Artificial Neural Network and Agility", Selva Staub et al. / Procedia - Social and Behavioral Sciences, 195, pp. 1477-1485, 2015.

[22] Rajarajan, Jagadeesh. "What is Multilayer perceptrons using backpropagation algorithm, in simple words?"Quora. https://www.quora.com/What-isMultilayer-perceptrons-using-backpropagation-algorithm-insimple-words. 23 February 2015.

[23] N. Zhang, S. Shen, A. Zhou and Y. Xu, "Investigation on Performance of Neural Networks Using Quadratic Relative Error Cost Function", IEEE access, 2016, doi: 10.1109/ACCESS.2019.2930520.

[24] H. Koivo,” Neural networks: Basics using MATLAB Neural Network Toolbox”, February 1, 2008

[25] F. Saadaoui, K. Mammar, A, Hazzab, "Modeling of photovoltaic system with maximum power point tracking control by neural networks", International Journal of Power Electronics and Drive System (IJPEDS) Vol. 10, No. 3, Sep 2019, pp. 1575-1591.

\section{BIOGRAPHIES OF AUTHORS}

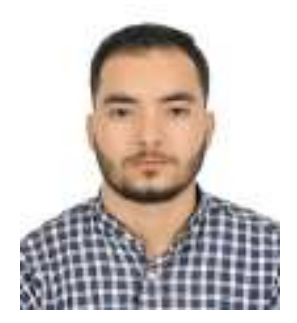

Jarmouni Ezzitouni, student, received his master degree in electrical engineering from faculty of science and technology Settat, in 2019, and he is currently a qualified secondary school mathematics teacher, at the Ministry of National Education, Morocco. His research areas include, smart grid, renewable energy and artificial intelligence. Laboratory of RadiationMatter and Instrumentation (RMI), The Faculty of Sciences and Technology, Hassan 1st University, Morocco. BP : 577, route de Casablanca. Settat, Morocco.

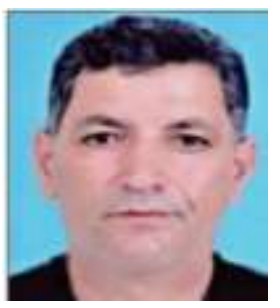

Ahmed Mouhsen, received his Ph.D. degree in Electronics from the University of Bordeaux, France, in 1992, and he is currently a Professor at the Electrical Engineering Department, Faculty of Sciences and Technologies, Hassan I University, Settat, Morocco. His research interest focuses on embedded systems, wireless communications and information technology. Laboratoire d'Ingénierie, de Management Industriel et d'Innovation (LIMII) Faculté' des Sciences et techniques (FST) Hassan First Université BP : 577, route de Casablanca. Settat, Morocco.

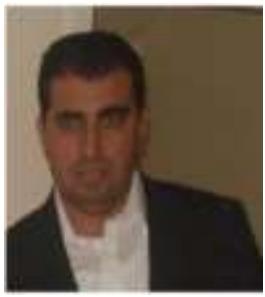

Mohamed Lamhamdi, holds a (2008) in materials and technology of electronics components from Paul Sabatier University Toulouse France. After four years' research engineer Grand Gap Rectifier project at STMicroelectronics \& GREMAN-University of Tours. in November 2011 he has been an assistant professor at national school of applied science khouribga Morocco, where he became the technical manager of the Electronics Signals and Systems (ESS) group. in January 2018, he joined the faculty of science and technology in Settat, Morocco, where he became member of the RMI Laboratory (Rayonnement-Matière \& Instrumentation). Current research topics include, MEMS sensors for RF applications, materials sciences, intelligent systems and energy.

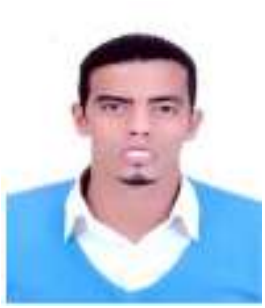

Zakarya BENIZZA, was born in KENITRA, Morocco, in 1985. He is Ph.D. candidate in the Faculty of Sciences and Technology, Hassan first University, Morocco. He is the Data Center responsible in university Hassan1st Settat Morocco since 2010, he received the Master degree in System and Network from University Hassan first, Settat, Morocco. Member of Engineering, Industrial Management and Innovation (IMII) Laboratory. 